\title{
A Comparative Study of Endoscopic Endonasal Dacryocystorhinostomy with and without Intraoperative Mitomycin-C Application
}

\author{
Raman Wadhera, Sat Paul Gulati, Ashok Kumar Khurana, Harikesh Sharma, Vijay Kalra, Anju Ghai
}

\begin{abstract}
Aim: To evaluate the role of intraoperative mitomycin-C application in primary endoscopic endonasal dacryocystorhinostomy (DCR) and compare the results with conventional endoscopic endonasal DCR.
\end{abstract}

Study design: Prospective comparative interventional study. Setting: Tertiary referral hospital.

Materials and methods: Fifty patients in the age group of 16 to 50 years presenting with symptoms and signs suggestive of nasolacrimal duct blockage refractory to conventional medical treatment were included in the study. They were assigned randomly into two groups of 25 patients each. G roup A patients underwent endoscopic endonasaI DCR followed by application of mitomycin-C. Group B patients underwent endoscopic endonasal DCR without application of mitomycin-C. The two groups were compared with regard to success rate and complications. The main outcome measures for success were the resolution of epiphora and patency with lacrimal irrigation.

Results: After 1 year, 24 patients (96\%) in each group had complete relief from their symptoms while one patient $(4 \%)$ had no relief. Syringing was patent in 24 patients $(96 \%)$ in each group and blocked in one patient (4\%) after 1 year of surgery.

Conclusion: The present study did not show any additional benefit of using mitomycin- $\mathrm{C}$ at the stoma site after primary endoscopic endonasal DCR in terms of success rate.

Keywords: Dacryocystorhinostomy, Endoscopic, Mitomycin-C, Syringing.

How to cite this article: Wadhera R, Gulati SP, Khurana AK, Sharma H, Kalra V, G hai A. A Comparative Study of Endoscopic Endonasal Dacryocystorhinostomy with and without Intraoperative Mitomycin-C Application. Clin Rhinol An Int J 2013;6(1):5-9.

\section{Source of support: Nil \\ Conflict of interest: None}

\section{INTRODUCTION}

Commonest cause of epiphora is obstruction in the drainage channel of normally produced tear fluid. The obstruction can be anywhere in the drainage pathway starting from the lacrimal punctum to lower end of nasolacrimal duct. In adults, about $70 \%$ of obstruction in lacrimal drainage apparatus occurs at junction of lower end of lacrimal sac and upper end of nasolacrimal duct. ${ }^{1}$ In most cases of the lacrimal system obstruction, the watery discharge from the eyes gradually acquires a mucopurulent or purulent character due to superadded infections promoted by the stagnation in lacrimal sac which acts as a constant reservoir of infected material.
Obstruction of lacrimal pathways is either congenital or acquired. Congenital causes include congenital nasolacrimal duct obstruction, lacrimal fistula, congenital dacryocystocele, lacrimal duct cysts and mass lesions like meningoencephalocele, capillary hemangioma, dermoid cyst, nasal glioma, lacrimal sac tumors. ${ }^{2}$ A cquired nasolacrimal obstruction may be primary or secondary. Primary obstructions are associated with fibroinflammatory process of unknown etiology. Secondary causes include infections, neoplasms, trauma, foreign bodies, melanin casts, dacryolithiasis, sarcoidosis, W egener's granul omatosis and radiation therapy. ${ }^{3}$ Primary acquired nasolacrimal duct obstruction is the most common cause of lacrimal obstruction in adults. Once dacryocystitis is well established, it becomes intractable, has little tendency to resolve with medical treatment, so the surgical treatment remains the only choice for management.

Endoscopic endonasal dacryocystorhinostomy (DCR) is a refinement over the external approach in that it avoids an external incision and subsequent scar formation and preserves the lacrimal pump mechanism of the orbicularis muscle. It is particularly useful in revision of external DCR cases where avoidance of an external incision and subsequent scarring gives it an advantage. ${ }^{4} 0$ ther advantages like one-stage procedure to correct associated nasal pathology, avoidance of injury to medial canthus, lesser operating time, minimal bleeding, lesser hospital stay are also there. Despite of its advantages, various causes of failure of endoscopic endonasal DCR have been mentioned. ${ }^{5}$ Osteotomy closure by granulation tissue has been reported as the most important reason of failure in endoscopic $D C R .{ }^{5,6}$ A ttempts have been made to improve the success rate of lacrimal surgery by using balloon catheters, stents, lasers and antimetabolites. Endoscopic balloon catheter dacryoplasty provides complete relief or substantial improvement in a significant number of patients with incomplete nasolacrimal duct obstruction. ${ }^{7}$ Laser-assisted $D C R$, performed either through an endocanalicular, transconjunctival or endonasal approach, yields the advantages of less bleeding, faster recovery and elimination of external scar. ${ }^{8}$

Some surgeons have advocated the use of antimetabolites to augment DCR surgery. Fibrous tissue growth, scarring and granulation tissue formation during 
the healing process decrease the created surface area of osteotomy site, leading to surgical failure. M itomycin- $C$ derived from Streptomyces caespitosus is an alkylating antibiotic. It reduces fibroblast collagen synthesis by inhibiting DNA -dependent RNA synthesis and can suppress cellular proliferation in any period of the cell cycle. When used as a topical $0.5 \mathrm{mg} / \mathrm{ml}$ solution, intraoperative application of mitomycin- $\mathrm{C}$ affects the wound healing process. Modulation of the wound healing response to prevent excessive scar formation can play a major role in endoscopic lacrimal surgery. ${ }^{9}$ The present study was conducted to evaluate the success rate and to compare the results of primary endoscopic endonasal DCR with and without intraoperative mitomycin- $\mathrm{C}$ applications.

\section{MATERIALS AND METHODS}

The study was conducted in the Departments of Otorhinolaryngology and Ophthalmology, Pt BD Sharma Postgraduate Institute of M edical Sciences, Rohtak. Fifty consecutive patients in the age group of 16 to 50 years presenting with symptoms and signs suggestive of nasolacrimal duct blockage refractory to conventional medical treatment were included in the study. They were assigned randomly into two groups of 25 patients each. Group A patients underwent endoscopic endonasal DCR followed by application of mitomycin-C. Group B patients underwent endoscopic endonasal DCR without application of mitomycin-C. Patients having the marked deviation of nasal septum on same side, chronic sinusitis, nasal polyps, severe bony deformity of lacrimal sac fossa (post-traumatic), bleeding disorders, nasal tumors and history of previous DCR were not included in the study.

Departmental board of postgraduate studies of our institute approved this entire study. Informed consent was obtained from the patients before the surgery. Patients were operated under local anesthesia. A fter appropriate premedication for sedation, nasal packing soaked in $4 \%$ lignocaine was placed anterior to the middle turbinate for 5 minutes. The area of lateral wall of the nose anterior, above and bel ow the anterior attachment of middle turbinate was infiltrated with lignocaine $2 \%$ with 1:100,000 adrenaline. Both $0^{\circ}$ and $30^{\circ}$ endoscopes were used during surgery. A horizontal incision was made with help of sickle knife above and in front of the anterior attachment of middle turbinate and another horizontal incision was made anterior to the insertion of inferior turbinate. A vertical incision was made joining the two horizontal incisions over frontal process of maxilla. M ucoperiosteal flap was raised using F reer elevator and it was removed using B lakesley forceps. Frontal process of maxilla was identified and it was removed using $K$ errison punch. Thin lacrimal bone was removed using throughcutting forceps. The bony window was further enlarged, with rongeurs or a high speed drill with a cutting burr, to a vertical dimension of at least 10 to $12 \mathrm{~mm}$. The medial wall of the lacrimal sac was tented with lacrimal probe by an eye surgeon. The incision was given over the medial wall of sac using sickle knife. Ball probe was used, if required, to break adhesions between medial and lateral wall. The medial wall of sac was removed with hel p of through-cutting forceps. Syringing was done using normal saline to conform the patency. In group A patients, a surgical sponge soaked in $0.5 \mathrm{mg} / \mathrm{ml}$ solution of mitomycin-C was applied to the mucosal border of the rhinostomy site for 5 minutes under endoscopic visualization. M aximum care was taken in order to have all circumferential mucosa in contact with the sponge. A fter removal of the sponge, the area was irrigated thoroughly with saline solution and aspirated with an intranasal aspirator. A change in the color of the nasal mucosa from red to white gray was visible immediately after application. M itomycin-C was not used in group B patients. $\mathrm{N}$ asal cavity was packed with roll gauge immersed in antibiotic ointment. Pack was removed on next day. A n oral antibiotic, antibiotic eye drops, saline nasal drops, steroid nasal spray and analgesic were advised to the patient in the postoperative period.

Regular follow-up of patients was done at 1st w eek, 6 th week, 12th week and 1 year. On each visit, lacrimal irrigation and nasal endoscopy were done. The two groups were compared with regard to complications as well as success rate. The main outcome measures for success were the resolution of epiphora and patency with lacrimal irrigation. The main outcome determinants for complications were the presence or absence of delayed wound healing, wound necrosis, infection or excessive bleeding. We documented the subjective symptoms and classified them as: Complete relief, partial relief and no relief from the symptoms. Syringing was documented as: Patent, partially patent and blocked. The clinician who did syringing was blinded to information about clinical data and group of patient.

The data was subjected to Student's t-test and $\chi^{2}$ analyses.

\section{RESULTS}

In our study, the male to female ratio was $2: 3$ in group $A$ and 8:17 in group B. A ge of patients ranged from 16 to 50 years. The mean age was $32.4 \pm 10.28$ years in group $A$ and $33.2 \pm 9.30$ years in group $B$. There was no significant difference in mean age between the two groups $(p>0.05)$. A Il the patients had unilateral nasolacrimal duct obstruction. 
A Comparative Study of Endoscopic Endonasal Dacryocystorhinostomy with and without Intraoperative Mitomycin-C

The commonest presenting symptom was tearing from the eyes seen in all the patients in both groups. Other symptoms noted were, purulent discharge, in $32 \%$ patients of group $A$ and $24 \%$ of group $B$ and swelling over the lacrimal sac, i.e. mucocele in $12 \%$ patients of group $A$ and $8 \%$ of group $B$.

The duration of symptoms varied from 2 to 18 months with majority of patients in both groups presenting within 10 months of onset of symptoms. The mean duration of symptoms was found to be $8.76 \pm 4.22$ months in group $A$ and $8.44 \pm 3.69$ months in group $B$. T here was no significant difference in duration of symptoms betw een the two groups $(p>0.05)$.

On syringing, the nasolacrimal duct was found to be blocked in all the 50 patients.

$M$ iddle turbinate head was resected, where it was found enlarged. The middle turbinate head resection was done in five patients in group $A$ and six patients in group $B$.

No nasal or gastrointestinal irritation was observed during application of mitomycin-C. During the follow-up period, no complications, such as delayed wound healing, abnormal nasal bleeding, mucosal necrosis or infection, were noted in any patient in both the groups. In group A, mild bleeding was observed in postoperative period in one patient. While in group $B$, two patients had mild bleeding in postoperative period. Bleeding subsided with conservative treatment in all patients.

A fter 1 year, 24 patients (96\%) in each group had complete relief from their symptoms while one patient (4\%) had no relief $(p>0.05)$ (Table 1). Syringing was patent in 24 patients (96\%) in each group and blocked in one patient $(4 \%)$ after 1 year of surgery $(p>0.05)$ (Table 2$)$.

\section{DISCUSSION}

M itomycin- $C$ has been used to modulate fibrosis after glaucoma and pterygium surgery. R eports on the usefulness of mitomycin-C in DCR for preventing postoperative fibrosis and rhinostomy closure demonstrate mixed findings. Till date, only few studies are available to evaluate the role of intraoperative mitomycin-C application in endoscopic endonasal DCR.

$\mathrm{K}$ ao et al, ${ }^{10} \mathrm{~L}$ iao et al, ${ }^{11}$ Roozital ab et al ${ }^{12}$ and $\mathrm{Y}$ ou and Fang $^{13}$ evaluated the role of intraoperative mitomycin- $C$ in external DCR. K ao et al, ${ }^{10}$ Liao et al, ${ }^{11}$ and $\mathrm{Y}$ ou and $\mathrm{Fang}{ }^{13}$ concluded that intraoperative mitomycin- $C$ application was effective in increasing the success rate of external $D C R$ surgery, whereas Roozitalab et al ${ }^{12}$ concluded that mitomycin- $C$ does not change the success rate of this procedure.

U gurbas et al performed endoscopic intranasal DCR and applied $0.5 \mathrm{mg} / \mathrm{ml}$ solution of mitomycin-C to the osteotomy site for 2.5 minutes intraoperatively. Specimens from four patients were collected during surgery and at 15 days, 1 month, 3 months and 6 months after surgery. M icroscopic examination of specimens of the mitomycin- $C$ group revealed attenuated epithelium with intracytoplasmic vacuoles. Normal epithelium without vacuoles was seen in the specimens of the control group. The control specimens had a dense and normocellular connective tissue compared with the hypocellular and looser connective tissue of the mitomycin- $C$ treated group. They suggested that by causing a decrease in density and cellularity of mucosa, topical use of mitomycin- $C$ may enhance the success of surgery. ${ }^{14}$ Camara et al conducted a study to evaluate the role of intraoperative mitomycin- $C$ in endonasal endoscopic laserassisted DCR. The success rate of the mitomycin-C group was $99.2 \%$ compared with $89.6 \%$ in the control group. Their study supported the safety and efficacy of the intraoperative use of mitomycin-C. ${ }^{15}$ But, Zilelioglu et al did not find any change in the success rate after using intraoperative mitomycin-C in endoscopic endonasal DCR. ${ }^{9} \mathrm{~J}$ avate and Pamintuan noted a success rate of $98 \%$ in 117 patients who

\begin{tabular}{|c|c|c|c|c|c|c|}
\hline & \multicolumn{3}{|c|}{ Group $A(n=25)$} & \multicolumn{3}{|c|}{ Group B $(n=25)$} \\
\hline & 1st week & 12th week & 1 year & 1st week & 12th week & 1 year \\
\hline No. of patients with complete relief & 22 & 24 & 24 & 23 & 24 & 24 \\
\hline No. of patients with partial relief & 2 & 0 & 0 & 2 & 0 & 0 \\
\hline No. of patients with no relief & 1 & 1 & 1 & 0 & 1 & 1 \\
\hline
\end{tabular}

\begin{tabular}{|c|c|c|c|c|c|c|}
\hline & \multicolumn{3}{|c|}{ Group A ( $n=25)$} & \multicolumn{3}{|c|}{ Group B $(n=25)$} \\
\hline & 1st week & 12th week & 1 year & 1st week & 12th week & 1 year \\
\hline No. of patients with syringing patent & 21 & 24 & 24 & 22 & 24 & 24 \\
\hline No. of patients with syringing partially patent & 3 & 0 & 0 & 3 & 0 & 0 \\
\hline No. of patients with syringing blocked & 1 & 1 & 1 & 0 & 1 & 1 \\
\hline
\end{tabular}


underwent endonasal $D C R$ using radiofrequency instruments for mucosa removal followed by mitomycin-C application, followed by placement of a double stent. ${ }^{16}$

In our study, male to female ratio was 2:3 in group A and $8: 17$ in group $B$. The increased incidence of dacryocystitis seen in females cannot be adequately explained. Sperkelsen and B arberan have ventured forth to attribute it to the use of cosmetics by females, especially on the rim of the lower eyelid. ${ }^{4} 0$ thers have proposed that the osseous nasolacrimal canal is longer and narrower in women than in men. ${ }^{17}$

We used mitomycin- $C$ in concentration of $0.5 \mathrm{mg} / \mathrm{ml}$ for 5 minutes over the stoma site. Other authors have used it for time duration ranging from 2.5 to 30 minutes. $9,10,11,13,14$ Shortened period of application, for this relatively benign disease, may decrease the possible penetration of drug beyond the surgical borders. ${ }^{9}$ Intraoperative application of mitomycin-C does not cause any systemic problem since it is not absorbable from gastrointestinal tract. There were no major intraoperative and postoperative complications in our study. Thus, intraoperative use of mitomycin- $C$ seems to be safe.

A s the small size of rhinostomy lowers the success rate, large rhinostomy was created in our patients by removing thick bone of frontal process of maxilla along with thin lacrimal bone. Bony rhinostomy extended from above the middle turbinate attachment to the level of the midpoint of the maxillary line inferiorly. L acrimal stenting was not done in any patient. All the patients had been followed up for 1 year. The average onset of ostium closure with granulation tissue formation after endoscopic endonasal DCR is reported to be 7.5 to 12.7 weeks. ${ }^{14}$ A nalysis of Boush et al series also showed that the majority of the surgical failures occurred within 4 months after endoscopic surgery. ${ }^{5}$ This indicates that the critical period is 4 months after endoscopic surgery.

With all these results, it can be concluded that endoscopic endonasal $D C R$ proves beneficial in patients of acquired nasolacrimal obstruction. The creation of the largest possible ostium minimizes the risk for subsequent stenosis and closure of the lacrimal ostium. The beneficial effect of mitomycin-C as a surgical adjunct is thought to be related to its potent inhibition of fibroblast proliferation. It is considered to increase the success rate of endoscopic endonasal DCR. B ut after 1 year of follow-up, the success rate was $96 \%$ in mitomycin-C group as well as in control group. Thus, our study did not show any additional benefit of using mitomycin- $C$ at the stoma site after primary endoscopic endonasal DCR in terms of success rate.

\section{REFERENCES}

1. Roper HM J. Stallard's eye surgery (7th ed). B ombay: V erghese Publishing House 1989:135-62.

2. K apadia M K , Freitag SK, W oog J J . Eval uation and management of congenital nasolacrimal duct obstruction. Otolaryngol Clin N A m 2006;39(5):959-77.

3. M ills DM, M eyer DR. A cquired nasolacrimal duct obstruction. Otolaryngol Clin N A m 2006;39(5):979-99.

4. Sperkelsen M B, Barberan M T. Endoscopic dacryocystorhinostomy: Surgical techniques and results. L aryngoscope 1996;106:187-89.

5. Boush GA, Bradlev NL, Dortzbach RK. Results of endonasal laser-assisted dacryocystorhinostomy. O phthalmology 1994; 101:955-59.

6. Kong YT, Kim TI, Byung WK. A report of 131 cases of endoscopic laser lacrimal surgery. Ophthalmology 1994;101:1793-800.

7. Couch SM, White WL. Endoscopically assisted balloon dacryoplasty treatment of incomplete nasolacrimal duct obstruction. O phthalmology 2004;111(3):585-89.

8. Moore W M, B entley CR, Olver J M. Functional and anatomic results after two types of endoscopic endonasal dacryocystorhinostomy: Surgical and holmium laser. Ophthalmology 2002;109(8):1575-82.

9. Zilelioglu G, Ugurbas SH, A nadolu $Y, A$ kiner $M, A$ kturk $T$. A djunctive use of mitomycin- $C$ on endoscopic lacrimal surgery. Br J Ophthalmol 1998;82:63-66.

10. Kao SCS, Liao CL, Tseng JHS, Chen MS, Hou PK. Dacryocystorhinostomy with intraoperative mitomycin-C. Ophthalmology 1997; 104:86-91.

11. Liao SL, K ao SCS, T seng JHS, Chen M S, Hou PK. Results of intraoperative mitomycin-C application in dacryocystorhinostomy. $\mathrm{BrJ}$ O phthalmol 2000;84(8):903-06.

12. Roozitalab MH, A mirahmadi M, Namazi MR. Results of the application of intraoperative mitomycin $C$ in dacryocystorhinostomy. Eur J Ophthalmol 2004;14(6):461-63.

13. Y ou $\mathrm{YA}$, Fang $\mathrm{CT}$. Intraoperative mitomycin- $\mathrm{C}$ in dacryocystorhinostomy. Ophthal Plast Reconstr Surg 2001;17(2):115-19.

14. U gurbas SH, Zilelioglu G, Sargon M F, A nadolu Y, A kiner M, A kturk T. Histopathologic effects of mitomycin-C on endoscopic transnasal dacryocystorhinostomy. Ophthalmic Surgery and L asers 1997;28(4):300-04.

15. Camara J G, B engzon AU, Henson RD. The safety and efficacy of mitomycin- $C$ in endonasal endoscopic laser assisted dacryocysto-rhinostomy. Ophthal Plast Reconstr Surg 2000;16(2):114-18.

16. J avate R, Pamintuan F. Endoscopic radiofrequency-assisted dacryocystorhinostomy with double stent: A personal experience. Orbit 2005;24(1):15-22.

17. GroessI SA, Sires BS, Lemke B N. A n anatomic basis for primary acquired nasolacrimal duct obstruction. A rch Opthalmol 1997;115(1):71-74.

\section{ABOUT THE AUTHORS}

\section{Raman Wadhera}

Professor, Department of Otorhinolaryngology, Pt. BD Sharma Post Graduate Institute of M edical Sciences, Rohtak, Haryana, India 
A Comparative Study of Endoscopic Endonasal Dacryocystorhinostomy with and without Intraoperative Mitomycin-C

Correspondenceaddress: 19/9 J, M edical Enclave, Rohtak-124001 Haryana, India, Phone: 094162-43616, 01262-212860, e-mail: dr.wadhera@yahoo.com

\section{Sat Paul Gulati}

Senior Professor and Head, Department of Otorhinolaryngology Pt. BD Sharma Post Graduate Institute of M edical Sciences, R ohtak Haryana, India

\section{Ashok Kumar Khurana}

Senior Professor, Department of O phthalmology, Pt. BD Sharma Post Graduate Institute of $\mathrm{M}$ edical Sciences, R ohtak, Haryana, India

\section{Harikesh Sharma}

Resident, D epartment of Otorhinolaryngology, Pt. BD Sharma Post Graduate Institute of M edical Sciences, R ohtak, Haryana, India

\section{Vijay Kalra}

Assistant Professor, Department of Otorhinolaryngology, Pt. BD Sharma Post Graduate Institute of M edical Sciences, R ohtak, Haryana India

\section{Anju Ghai}

Professor, Department of A nesthesiology, Pt. BD Sharma Post Graduate Institute of M edical Sciences, Rohtak, Haryana, India 